\title{
De sobrevivir a vivir
}

\author{
Miguel Ángel Hernández Alvarado
}

\begin{abstract}
1o largo de todo el período de contingencia, la cotidianeidad ha cambiado, al pasar por situaciones que la llevan de un lado a otro, agotando la expectativa de volver a La antigua normalidad, que se ve cada vez más lejana. En esta nostalgia por cómo eran las cosas, la constante ha sido adaptarse a lo que ocurre, a los eventos que suceden y sorprenden, así como a los cambios, con sus consecuencias de diversas dimensiones.
\end{abstract}

Es así como las pérdidas, los accidentes y las batallas van esculpiendo el nuevo rostro de la neonormalidad, que se promete latente y próxima. Sobre esta nueva cara, el presente número de la Revista Digital Universitaria nos regala líneas para aprender, cuestionar y reflexionar en torno a la adaptación, identidad, emergencia y potencialidad humanas y de la naturaleza de adecuarse a lo que sucede, para crear nuevas normalidades.

Un aspecto importante acerca de la construcción y percepción colectivas de lo social, en esta edificación de nueva normalidad, es el referente a lo educativo. En este número de la RDU hay un par de artículos sobre el tema. El primero de ellos, "Universitarios mexicanos: Io mejor y lo peor de la pandemia de coviD-19", expone la percepción estudiantil acerca de lo bueno y lo malo durante la contingencia. Mediante los resultados de un cuestionario, los estudiantes nos dejan ver sus impresiones sobre pérdidas y ganancias en esta crisis sanitaria.

El segundo, llamado "Aprendizaje autodirigido en la educación superior: una perspectiva para la modalidad en línea", nos presenta la definición, relevancia y componentes del aprendizaje autodirigido. También nos impulsa a pensar sobre la posibilidad y los desafíos de este proceso formativo en la situación de la educación superior en nuestro contexto actual de educación remota.

Desde otro enfoque, en una serie de artículos sobre la vida natural de otras especies, este número de la RDu nos lleva a conocer diversas conductas de algunos organismos. El escrito "Insectos suicidas: irregularidades de su comportamiento" nos interpela en torno al valor del autosacrificio para conservar a la comunidad, los genes o la descendencia. En el mismo sentido, en "Comunicación entre bacterias: el WhatsApp de Pseudomonas aeruginosa" descubrimos las "conductas" de estas bacterias y el papel indispensable de la comunicación para el triunfo de la especie. Esto lo demuestran sus acciones de interacción de comunicación inmediata, que bien parecen un WhatsApp pero con luz.

Dol: http://doi.org/10.22201/cuaieed.16076079e.2021.22.3.0 
"De sobrevivir a vivir"

También en este número se puede apreciar que las conductas de los seres vivos fortalecen la supervivencia. Muestra de ello es la variedad de especies que da a conocer el artículo "Parásitos y pelos: historias de la selva de Chamela", parte de la biodiversidad del lugar; así como el artículo "Arañas: tejiendo un eslabón crucial para le equilibrio de los agroecosistemas", que habla de la interacción de las arañas con los agrocultivos, y que describe su uso como controladoras de plagas. De esto podemos reflexionar cómo la depredación de los arácnidos y la adaptabilidad de los parásitos equilibran un entorno en el que luchan por sobrevivir, pues se ven amenazados (en su diversidad y adaptabilidad) por la acción humana.

En el escenario de sobrevivencia a la pandemia, la Revista presenta artículos sobre la ciencia del cuerpo, que nos revelan caminos asombrosos para comprender la dinámica de la vida que nos constituye. Un ejemplo es la exposición que se hace a modo de diálogo sobre la biotecnología, en la colaboración "Conversando de biología sintética en el gimnasio", y su utilidad para resolver necesidades y problemas de salud y de desarrollo. Por otro lado, el artículo "Aminoácidos no esenciales en la síntesis de partículas de oro y sus potenciales aplicaciones" desarrolla el valioso aporte de las nanopartículas como transporte para vacunas (tan fundamentales en nuestro contexto) y cómo el empleo de los metales puede contribuir en la salud humana.

Continuando con el tema de salud, este número nos comparte dos artículos al respecto. El primero, llamado "Bebidas azucaradas: la batalla contra el sobrepeso y la obesidad en México", presenta una discusión sobre las bebidas azucaradas y expone la relación entre la ley de impuestos y la disminución de su consumo, así como la aún alarmante cifra de abuso en la ingesta de azúcar en la dieta promedio nacional. El segundo, "Energías renovables y sustentabilidad: una eficiente forma de gestionar los recursos naturales", en cambio, habla sobre la salud del planeta y el beneficio que implica el uso de energías renovables, así como la educación en su uso y desarrollo, éstas como acciones que pueden prevenir el colapso de la biósfera. Por lo tanto, la salud personal y el bienestar del planeta pueden ser resultado de una reflexión ética y medioambiental, que exige actitudes de autocuidado y sustentabilidad.

Esta adaptación, resiliencia y exhortación a la reflexión sobre la conservación y la salud nos pueden dar pistas sobre la adaptabilidad a las nuevas forma de vivir que estamos generado y de las que también somos responsables. Normalidades físicas y sociales que dependerán de lo que hacemos en esta adecuación personal y colectiva, resultado de la contingencia.

En ese sentido, este número de la RDu nos lleva también a reconocer que hay espacios que requieren ser transformados, para dejar de resistir o sobrevivir y empezar a ser habitados de forma común. Así, en el artículo “¿Dónde quedó el poder de las mujeres?" se cuestiona la accesibilidad al desarrollo laboral y profesional de las mujeres, las cuales aún son relegadas por el machismo implícito en las prácticas organizacionales, que no les permiten crecer. Resulta urgente que se vuelvan naturales las posibilidades, iguales para todos, de crecer como profesionales y trabajadores en cualquier organización. 
"De sobrevivir a vivir"

A esta misma resistencia y contribución de lucha se suma la aportación del artículo "¿Miradas desde adentro? Dinámicas de representación de mujeres yalaltecas en la actualidad". En él, se habla de visibilización de la comunidad, la intimidad y la identidad de las mujeres indígenas, mediante el ejercicio de la fotografía, que se sincretiza en la fotografía "Melina". Ésta, comenta la autora, es una obra performativa que atestigua y revela la presencia fuerte y determinante de la mujer para el desarrollo real de la sociedad.

Otro aspecto importante en medio de esta misma contingencia es la adaptación de las prácticas docentes. En la educación remota de emergencia la creatividad no sólo ha sobrevivido sino que ha sobrepasado todas las limitantes, dejando evidencia de su resiliencia y fortaleza. Dos muestras de ello son los productos que podemos ver en los artículos "¿Sabías que el japonés tiene miles de onomatopeyas?", sobre los Gifs para aprender japonés, y "El cómic y el arte pop", un video de ArtPop. Ambos son recursos digitales y son resultado de la vocación y el talento de dos académicas que han sabido responder ante la contingencia.

A lo largo de los artículos que le dan cuerpo, la Revista nos invita a pensar las formas que tiene la vida, las emociones, las relaciones sociales, y en sí el conocimiento, de adecuarse a los más diversos y cambiantes escenarios. Nos propone descubrir la capacidad de sobrevivir a los cambios y de vivir cualquier nueva normalidad con buenos resultados.

Las voces que dialogan en este número de la Revista crean un discurso de lucha, adaptabilidad, desarrollo y creatividad a los escenarios en que cada objeto estudiado habita. De igual manera, nos comparten una invitación a vivir (no sobrevivir) la realidad siempre cambiante, que promete nuevas formas de ser y de estar en ella, así como a aprender de la pandemia y la contingencia, con perspectiva de futuro, traduciendo este aprendizaje en acciones presentes de cambio e innovación. ¡Disfruten su lectura!

\section{Miguel Ángel Hernández Alvarado}

miguel hernandez@cuaieed.unam.mx orcid.org/0000-0003-2248-4336

Licenciado y Maestro en Pedagogía por la UNAM, Especialista en Desarrollo Humano y estudiante del Doctorado en Educación. Ha colaborado en organizaciones educativas públicas y privadas de nivel básico y superior en docencia, gestión, produccióny capacitación docente. Actualmente es Líder de Proyecto en la Subdirección de Investigación en Educación de la Coordinación de Universidad Abierta, Innovación Educativa y Educación a Distancia de la unAm. Sus líneas de investigación son Formación docente, Evaluación educativa, Desarrollo humano en prácticas escolares y Didáctica y emociones.

\section{Cómo citar este artículo}

* Hernández Alvarado, Miguel Ángel. (2021, mayo-junio). De sobrevivir a vivir. Revista Digital Universitaria (RDU), 22(3). http://doi.org/10.22201/cuaieed.16076079e.2021.22.3.0 